\title{
BMJ Open What non-technical skills competencies are addressed by Australian standards documents for health professionals who work in secondary and tertiary clinical settings? A qualitative comparative analysis
}

Monica Peddle, ${ }^{1}$ Margaret Bearman, ${ }^{2}$ Natalie Radomski, ${ }^{3}$ Lisa Mckenna, ${ }^{1}$ Debra Nestel $^{4}$

To cite: Peddle M, Bearman M, Radomski N, et al. What nontechnical skills competencies are addressed by Australian standards documents for health professionals who work in secondary and tertiary clinical settings? A qualitative comparative analysis. BMJ Open 2018;8:e020799. doi:10.1136/ bmjopen-2017-020799

- Prepublication history and additional material for this paper are available online. To view these files, please visit the journal online (http://dx.doi. org/10.1136/bmjopen-2017020799).

Received 27 November 2017 Revised 13 June 2018 Accepted 10 July 2018

D) Check for updates

(C) Author(s) (or their employer(s)) 2018. Re-use permitted under CC BY-NC. No commercial re-use. See rights and permissions. Published by BMJ.

For numbered affiliations see end of article.

Correspondence to Ms Monica Peddle; m.peddle@latrobe.edu.au

\section{ABSTRACT}

Objectives At minimum, safe patient outcomes are recognised as resulting from a combination of technical and non-technical skills. Flin and colleagues provide a practical framework of non-technical skills, cognitive, social and interpersonal, that complement technical skills, with categories identified as situational awareness, communication, team working, decision-making, leadership, coping with stress and managing fatigue. The aim of this research was to explore the alignment of categories and elements of non-technical skills with those in the published standards documents of several health professions in Australia.

Design A qualitative comparative analysis using document analysis and deductive coding examined, extracted and interpreted data from competency standards documents focusing on non-technical skills categories and elements.

Participants A purposive sample of 11 health professions competency standards documents required for registration in Australia.

Findings The 11 competency standards documents contained 1616 statements. Although standards documents addressed all non-technical skills categories, there was limited reporting of managing stress and coping with fatigue. Of the 31 elements included in the non-technical skills framework, 22 were not common to all health professions and 3 elements were missing from the standards documents. Additionally, the documents were composed differently with no common taxonomy and multifaceted statements.

Conclusion While commonalities identified in the standards documents related to non-technical skills categories are likely to support patient safety, gaps in associated elements may undermine their effectiveness. The notable lack of reference to stress and fatigue requires further attention for health professional well-being in Australia. A shared taxonomy with clear statements may offer the best support for collaborative practice and positive patient outcomes. Competency standards need to be flexible to respond to the emerging demands of current
Strengths and limitations of this study

- The study views standards documents from several professions using a singular lens of non-technical skills.

- Analytic rigour was established by the coding of a random selection of competency statements by all authors and presentation of sample statements from each code.

Only professions registered by Australian Health Professional Registration Agency were included.

- Caution must be exercised when comparing competency statements and proportionality as they may reflect different levels within the documents.

- Coding was challenging because there is not a common taxonomy and language across different health professions.

healthcare practice along with consumer and health service needs.

\section{INTRODUCTION}

There is consensus that medical error is a combination of human factors and system factors, ${ }^{12}$ with up to $80 \%$ of errors in healthcare associated with failures in non-technical skills such as communication, teamwork and decision-making. ${ }^{3}$ A deficit in the non-technical skills of surgeons can contribute to deterioration in technical performance. ${ }^{4}$ When nurses do not have the required skills to function as a member of a team, team effectiveness is impacted. ${ }^{5}$ When non-technical skills of medical emergency teams are rated as low, there has been an associated lower patient survival. ${ }^{6}$ Non-technical skills are described as 'the cognitive, social and personal resource 
Table 1 Categories and elements of non-technical skills

\begin{tabular}{|c|c|c|}
\hline Category & Definition & Elements \\
\hline $\begin{array}{l}\text { Situation } \\
\text { awareness }\end{array}$ & $\begin{array}{l}\text { 'The perception of the elements in the environment } \\
\text { within a volume of time and space, the comprehension } \\
\text { of their meaning and the projection of their status in the } \\
\text { near future. } .^{7}\end{array}$ & $\begin{array}{l}\text { 'Gathering information, } \\
\text { interpreting information, } \\
\text { anticipating future states. }{ }^{17}\end{array}$ \\
\hline Decision-making & $\begin{array}{l}\text { 'Decision-making can be defined as the process of } \\
\text { reaching a judgement or choosing an option, sometimes } \\
\text { called a course of action, to meet the needs of a given } \\
\text { situation. }{ }^{7}\end{array}$ & $\begin{array}{l}\text { 'Situation assessment-defining problem, } \\
\text { generating and considering one or more } \\
\text { response options, } \\
\text { selecting and implementing an option, } \\
\text { outcome review. }{ }^{17}\end{array}$ \\
\hline Communication & $\begin{array}{l}\text { 'Communication is the exchange of information, } \\
\text { feedback or response, ideas and feelings. It provides } \\
\text { knowledge, institutes relationships, establishes } \\
\text { predictable behaviour patterns, maintains attention to } \\
\text { the task, and is a management tool. }{ }^{17}\end{array}$ & $\begin{array}{l}\text { 'Send information clearly and concisely, } \\
\text { include context and intent during information } \\
\text { exchange, } \\
\text { receive information especially by listening, } \\
\text { identify and address barriers to } \\
\text { communication. }{ }^{7}\end{array}$ \\
\hline $\begin{array}{l}\text { Coping with } \\
\text { fatigue }\end{array}$ & $\begin{array}{l}\text { 'The state of tiredness which is associated with long } \\
\text { hours of work, prolonged periods without sleep, } \\
\text { requirements to work at times which are "out of sync" } \\
\text { with the body's biological or Circadian rhythms. }{ }^{17}\end{array}$ & $\begin{array}{l}\text { 'Identify causes of fatigue, } \\
\text { recognise effects of fatigue } \\
\text { implement coping strategies. }{ }^{17}\end{array}$ \\
\hline
\end{tabular}

skills that complement technical skills, and contribute to safe and efficient task performance'. ${ }^{2}$

Work led by Flin and colleagues identified the non-technical skills critical for safe and competent work practice in high-risk industries. They describe seven categories of non-technical skills, situation awareness, decision-making, communication, team working, leadership, managing stress and coping with fatigue, each containing a number of key elements (table 1). ${ }^{7}$ The non-technical skills framework represents an hierarchical structure of categories down to elements. ${ }^{8}$ Elements detail the specific skills and components of performance and constitute the main working level of the system. ${ }^{9}$ The framework has become an important construct on which performance in non-technical skills has been measured in clinical practice. ${ }^{10}$ The categories and elements provide 'a set of established constructs and a common vocabulary for learning about the important behaviours that influence safe and efficient task execution' 7 Evidence of application of these non-technical skills can be found in acute settings in healthcare. including anaesthesia, surgery, pharmacy, histopathology, intensive care, emergency and paramedicine. ${ }^{11}$

\section{COMPETENCY STANDARDS IN HEALTH PROFESSIONS}

Initial core competencies were detailed descriptors for each profession that described the essential values, 
knowledge, attitudes and skills. ${ }^{12} 13$ These initial competencies evolved to form the standards and expectations that became part of the prerequisites for current health professional registration. ${ }^{13}{ }^{14}$ Professional standards are defined as 'agreed professional standards that are measurable, allowing $\ldots$ behaviour to be observed and assessed while specific workplace tasks and roles are performed. ${ }^{15}$ Competency standards are used: to communicate scope of practice ${ }^{16}$; by health professionals to assess their own performance; to determine suitability for registration; to provide a framework and inform course curricula; to develop position descriptions and to underpin performance assessment. ${ }^{15}$

As standards outline desired characteristics and threshold competencies required for competent practice, ${ }^{17}$ and non-technical skills have been identified as an important component of competent practice, non-technical skills statements should be included in professional standards for registration of health professionals. ${ }^{3}$ Inclusion is supported by the findings of an investigation into the quality of healthcare in the USA published in 2000, To Err is Human, which recommended greater attention be paid to patient safety in performance standards and expectations for health professionals. ${ }^{3}$ Additionally, national committees in the USA call for attention to standards to address the significant problems associated with quality and safety in healthcare. ${ }^{18}$

The Australian Health Practitioner Registration Agency (AHPRA) is the overarching national agency responsible for regulating health professional registration in Australia. Each profession has a national regulatory board responsible for protecting the public; the boards set standards, codes and guidelines for registered health professionals. ${ }^{17} 19$ Additionally, each board is responsible for assessment of providers and their programmes of study to ensure they meet accreditation standards. ${ }^{17}$ The related nomenclature is complex and includes performance standards, competency-based standards, standards for practice and professional capabilities. We use the term standards documents to refer to the AHPRA documents.

There is a paucity of literature examining the alignment of professional standards with the non-technical skills framework developed by Flin et al. ${ }^{7}$ Previous comparative analysis undertaken aimed to compile robust lists of common domains of competence for application across multiple healthcare professions to support interprofessional education ${ }^{13}$ 20-22 and identify common themes for competencies in patient safety and quality improvement. ${ }^{23}$ Only one study was located that reported a comparison undertaken using the non-technical skills framework. Greig et $a l^{24}$ conducted an analysis of medical specialty curricula to identify the prevalence of non-technical skills. The authors reported that non-technical skills terms occurred infrequently and were most prevalent in critical care specialties, including anaesthesia, emergency and intensive care, with limited detail in assessment of non-technical skills. ${ }^{24}$ Non-technical skills are relevant across all practice settings and professions and are recognised as crucial for safe and competent patient care; however, little is known about how various standards documents, required for registration, address non-technical skills.

\section{RESEARCH QUESTION}

To address the perceived gap in the literature, we sought to answer the following question: what non-technical skills categories and elements are addressed by the Australian registration standards documents for health professionals who work in secondary and tertiary clinical settings?

\section{METHODS}

Using document analysis to examine, extract and interpret data, a qualitative comparative analysis was performed on the standards documents and non-technical skills categories and elements. Steps for the document analysis included finding, selecting, appraising and synthesising data. ${ }^{25}$ Ethical approval was not required as all documents analysed are in the public domain.

\section{Patient and public involvement}

No patients or public were involved in this research.

\section{Finding and selecting}

Standards documents of health professionals registered with APHRA who practise acute care (defined as 'a pattern of health care in which a patient is treated for a brief but severe episode of illness, for the sequelae of an accident or other trauma, or during recovery from surgery ${ }^{26}$ ) in secondary settings ('Services provided by hospitals, such as acute care, as well as services provided by specialists ${ }^{27}$ ) or in tertiary settings ('Highly specialised or complex services provided by specialists or allied health professionals ${ }^{, 27}$ ) were selected. These included the professions of Dentistry, Nursing, Medicine, Medical Radiation, Midwifery, Occupational Therapy, Pharmacy, Physiotherapy and Podiatry. The acute care context was selected as this is the predominate area of employment for new health professional graduates and makes up a large component of clinical placements for undergraduate students. The standards documents of the selected health professions were located through websites of relevant societies or associations (June, 2015) (online supplementary box 1). To ensure authenticity and currency of the documents retrieved for analysis, each standards document was reviewed and verified by a registered member of each profession. The Nursing and Midwifery Board of Australia approved new competency standards for Registered Nurses (first level) and Enrolled Nurses (second level) in January 2016. These new standards were included in our research.

\section{Qualitative analysis}

Content analysis using deductive data coding was employed. ${ }^{25}$ We used the categories and elements of non-technical skills developed by Flin $e t a l$ as a priori 
Table 2 Competency statements and levels of statements in standards documents

\begin{tabular}{|c|c|c|c|c|c|}
\hline Profession & Level one & Level two & Level three & Level four & Level five \\
\hline Dentistry & Domain & Description & & & \\
\hline Enrolled nurse & Domain & Standards & Indicators & & \\
\hline Medical radiation & Domain & $\begin{array}{l}\text { Capability } \\
\text { statement }\end{array}$ & Evidence & & \\
\hline Medicine & Learning Area & Category & Learning topic & $\begin{array}{l}\text { Competency or } \\
\text { capability }\end{array}$ & \\
\hline Midwifery & Domain & Competency & Element & Cues & \\
\hline Nurse practitioner & Standard & Statement & Cues & & \\
\hline $\begin{array}{l}\text { Occupational } \\
\text { therapy }\end{array}$ & Unit & Domain & $\begin{array}{l}\text { Performance } \\
\text { Criteria }\end{array}$ & Cues & \\
\hline Pharmacy & Domain & Standard & Element & $\begin{array}{l}\text { Performance } \\
\text { Criteria }\end{array}$ & Evidence examples \\
\hline Physiotherapy & Standards & Element & Criteria & Evidence & \\
\hline Podiatry & $\begin{array}{l}\text { Competency } \\
\text { Standard }\end{array}$ & Element & $\begin{array}{l}\text { Performance } \\
\text { Criteria }\end{array}$ & $\begin{array}{l}\text { Examples of } \\
\text { evidence }\end{array}$ & \\
\hline Registered nurse & Standard & Criteria & & & \\
\hline
\end{tabular}

Statements in levels identified by bolded italics were used in comparative analysis.

codes. ${ }^{7}$ Statements within the standards documents were initially coded to category codes and then further coded to element codes. Statements in the standards documents that did not align with a non-technical skills category were coded to an other category, such as those concerning technical standards. The aim was to produce an overall picture of the standards documents, with indications of frequency of categories and elements of non-technical skills. ${ }^{25}$ To ensure rigour of the analytic process, a selection of standards statements from all professions were coded by all authors, providing a benchmark for further coding completed by a single investigator (MP) who reviewed all selected documents. This investigator read all documents to identify meaningful and relevant statements related to non-technical skills that were coded accordingly.

\section{FINDINGS}

Each of the standards documents was composed differently. The documents contained multiple variations of descriptive statements at different levels of granularity as outlined in table 2. The hierarchy of statements ranged from two levels (Registered Nurse) to five levels (Pharmacy). The statements used for analysis were those containing consistent behavioural and measurable statements.

Standards documents of 11 professions were reviewed with a total of 1616 statements. All non-technical skills categories were found to be addressed in the standards documents (table 3). A total of 592 statements were coded to non-technical skills (NTS) categories with 27 statements coded twice. Any statement that did not align with the categories and elements of non-technical skills was coded to the other category. One thousand and twenty-four statements were coded to the other category.
Analysis identified 204 (34\%) statements coded to the communication category and $126(21 \%)$ to leadership. The decision-making category had $99(17 \%)$ statements, team working 95 (16\%), situational awareness had $53(9 \%)$, managing stress 12 (2\%) and coping with fatigue had $3(1 \%)$ statements. Of the 31 elements included in the study, 6 were common in all standards documents, 22 elements lacked commonality and 3 elements were missing from all standards documents.

The frequencies of non-technical skills categories identified in the standards documents selected for analysis are represented in figure 1, with the percentage breakdown of non-technical skills statements compared with other statements in each professional standards document in figure 2. Examples of coded statements are presented in online supplementary box 2 .

\section{DISCUSSION}

This study sought to identify what non-technical skills categories and elements are addressed by the Australian registration standards documents for health professionals who work in secondary and tertiary clinical settings. The non-technical skills categories addressed in the standards documents are communication, leadership, decision-making and team working. Less reference was made to situational awareness, and minimal reference was made to managing stress and coping with fatigue. There has been 'some' uptake of non-technical skills by the various professional bodies, but a more deliberate approach and systematic use of non-technical skills literature would be beneficial in future versions of these documents.

Six elements were common across the standards documents (table 3). The hierarchical nature of the non-technical skills framework suggests that successful achievement 


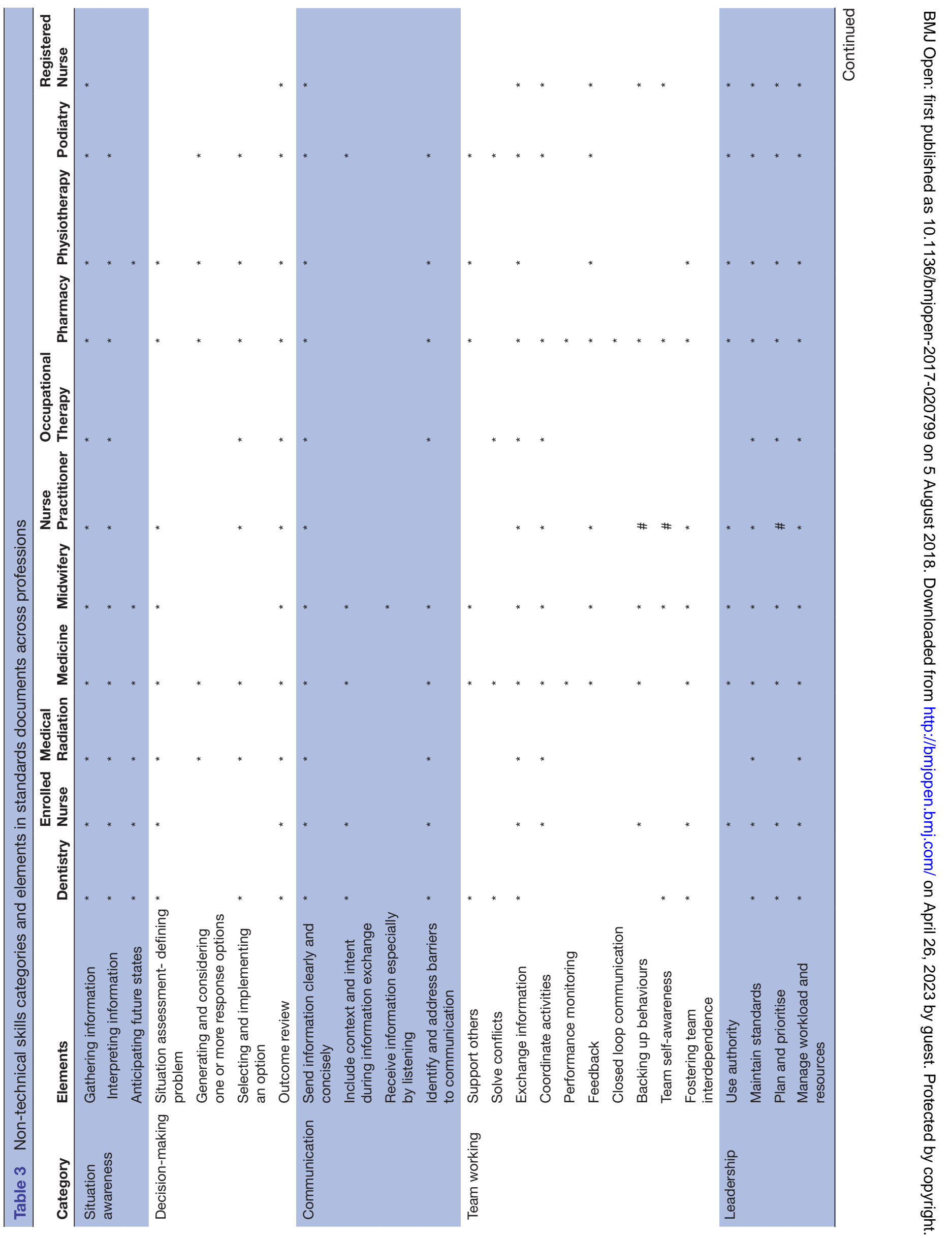




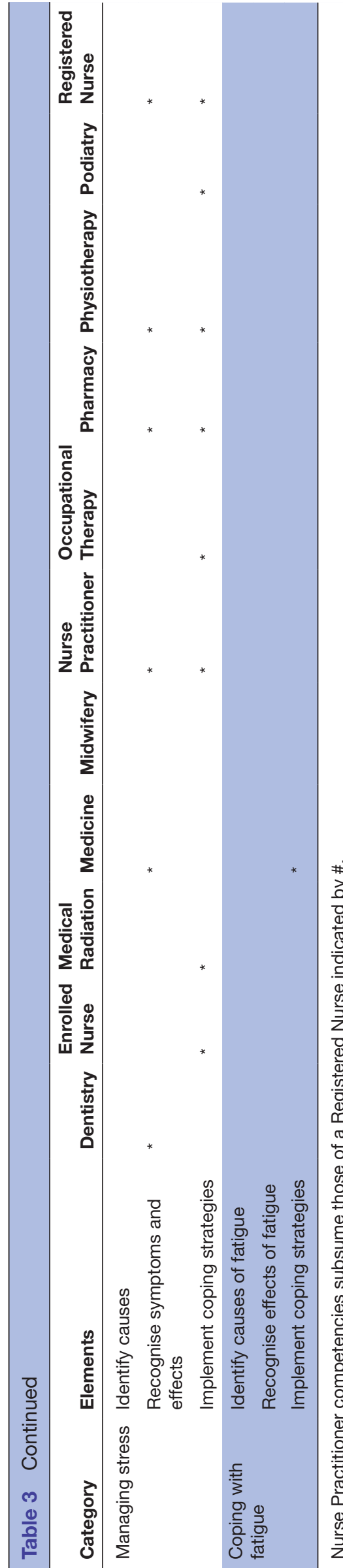

of non-technical skills categories may rest on the implementation of individual elements. As a large number of elements were not consistent or missing from the standards documents, doubts may be raised regarding the overall effectiveness of non-technical skills implemented in clinical practice. For example, closed loop communication was missing from the team working category in all professions but medicine, which may influence effective collaborative practice. Further, in the communication category, a notable omission from all but one profession, midwifery, was 'listening'. Active listening is identified as important in receiving information, essential for safe patient care. $^{72829}$ In the standards documents reviewed, the need to generate and consider one or more response options in the decision-making process was inconsistent. When making decisions, it is important to generate a number of potential options to be compared to determine which one best fits the situation, ${ }^{7}$ so this is clearly a limitation in some standards documents.

One positive finding from this study highlights that competencies commonly identified in literature underpinning effective interprofessional practice are present in the standards documents. These include clarity regarding other health professional roles, mutual respect and trust, communication, effective teamwork skills, a willingness to collaborate and contribute to shared plans and goal setting. ${ }^{30}$ These commonalities should encourage and support health professionals to intentionally and effectively work together to implement quality and safer healthcare. ${ }^{31} 32$

Two categories that were mostly absent from the standards documents are coping with fatigue and managing stress. Recent evidence suggests that current Australian junior medical officers' fatigue levels are significantly worse than the general population. ${ }^{33}$ Fatigue leads to decreased alertness and concentration, reduced motivation and productivity, impaired information processing and increased risks of accidents. ${ }^{34}$ The importance of managing stress in relation to patient outcomes and for the health and well-being of the health professional is highlighted by the relatively high incidence of work-related stress, burnout and suicide in health professionals. A recent report identified that the suicide rate for female health professionals in Australia was significantly higher compared with those in other occupations. ${ }^{35}$ While many organisations have released documents and guidelines to support health professional well-being, current published evidence suggests a need for further attention to consider omissions in the standards documents, particularly in the managing stress and coping with fatigue categories, to ensure health professional well-being.

The percentage of statements within standards documents for nursing, medicine and midwifery related to non-technical skills was higher compared with the other professions (figure 2). These professions are involved largely in acute patient care in secondary and tertiary settings. Professional standards documents for dentistry, occupational therapy, pharmacy, physiotherapy and 


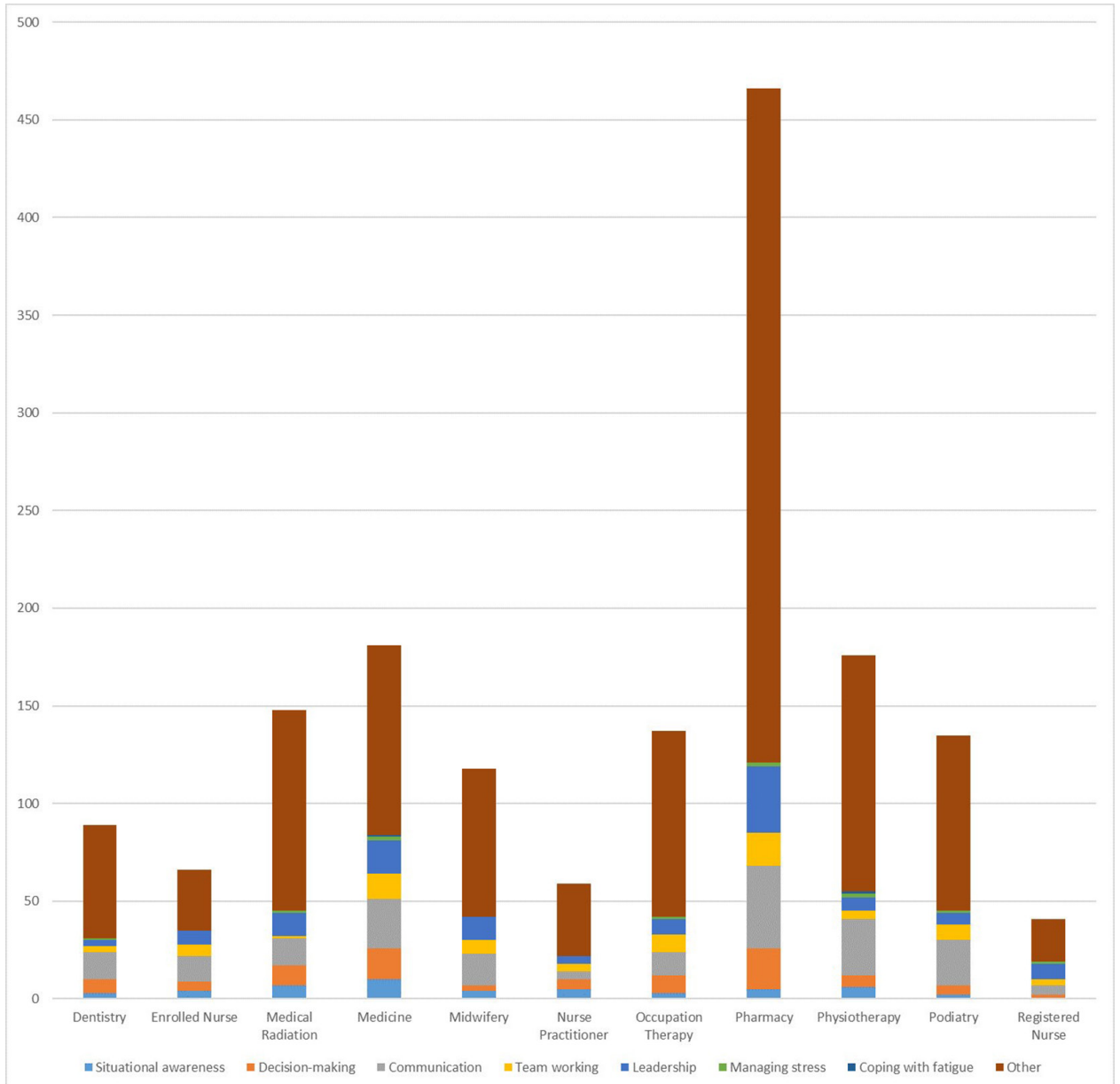

Figure 1 Categories of non-technical skills in standards documents by profession (each statement was coded to Flin et $\mathrm{al}^{7}$ (2013) categories and elements of non-technical skills. Any statement that fell outside these categories was coded to other).

podiatry have a lower proportion of competency statements addressing non-technical skills as defined by Flin et $a .^{7}$ While these professions practise in acute care, the predominate context of care is primary or community care. The development of the non-technical skills framework used in this research has tended to be from acute care areas in anaesthesia and surgery. ${ }^{36}$ In these settings, the patient is anaesthetised, therefore the non-technical skills categories and elements focus on co-ordination and communication between the interprofessional team and are less directly concerned with the patient. ${ }^{36}$ Additionally, each working environment has its own unique requirements for non-technical skills that are specific to the needs and characteristics of that profession. ${ }^{37}$ Hence, for professions practising mainly in primary and community care with alert and engaged patients, the identified categories and elements of non-technical skills developed by Flin et al may not have sufficient relevance.

This research highlights 'a lack of a common language describing the domains of health professionals and their specific competencies, ${ }^{20}$ and emphasised the siloed approach of individual national regulatory boards that has been reported as "counterintuitive to team-based care ${ }^{17}$ A common taxonomy across all standards documents has been proposed to provide a shared baseline. ${ }^{20}$
A shared interprofessional language is important to further facilitate and foster collaborative education and practice. Further, many statements contained 'multifaceted attributes related to collaborative attitudes, values, knowledge, skills and behaviours packaged together in one single statement'. ${ }^{31}$ It would be helpful for each profession to talk about the same thing in a clear unambiguous manner. A bold move would be to facilitate collaboration across the regulatory boards in Australia to review and clarify the standards documents to achieve a common taxonomy, with shared statements and a greater commonality of fundamental skills. ${ }^{17}$

Finally, a recent report from the Council of Australian Governments Health Council identifies that accreditation processes should ensure the healthcare workforce responds to changing healthcare needs and that currency of competency standards is maintained. ${ }^{17}$ However, the findings of this study question the ability of the regulatory bodies to respond to emerging drivers in practice to support the development of a flexible and responsive health workforce. ${ }^{17}$ It is important that all health professional regulatory boards, in Australia and internationally, pay attention to the standards documents for each profession to ensure they reflect contemporary practice and meet current consumer and health service needs. ${ }^{17}$ 


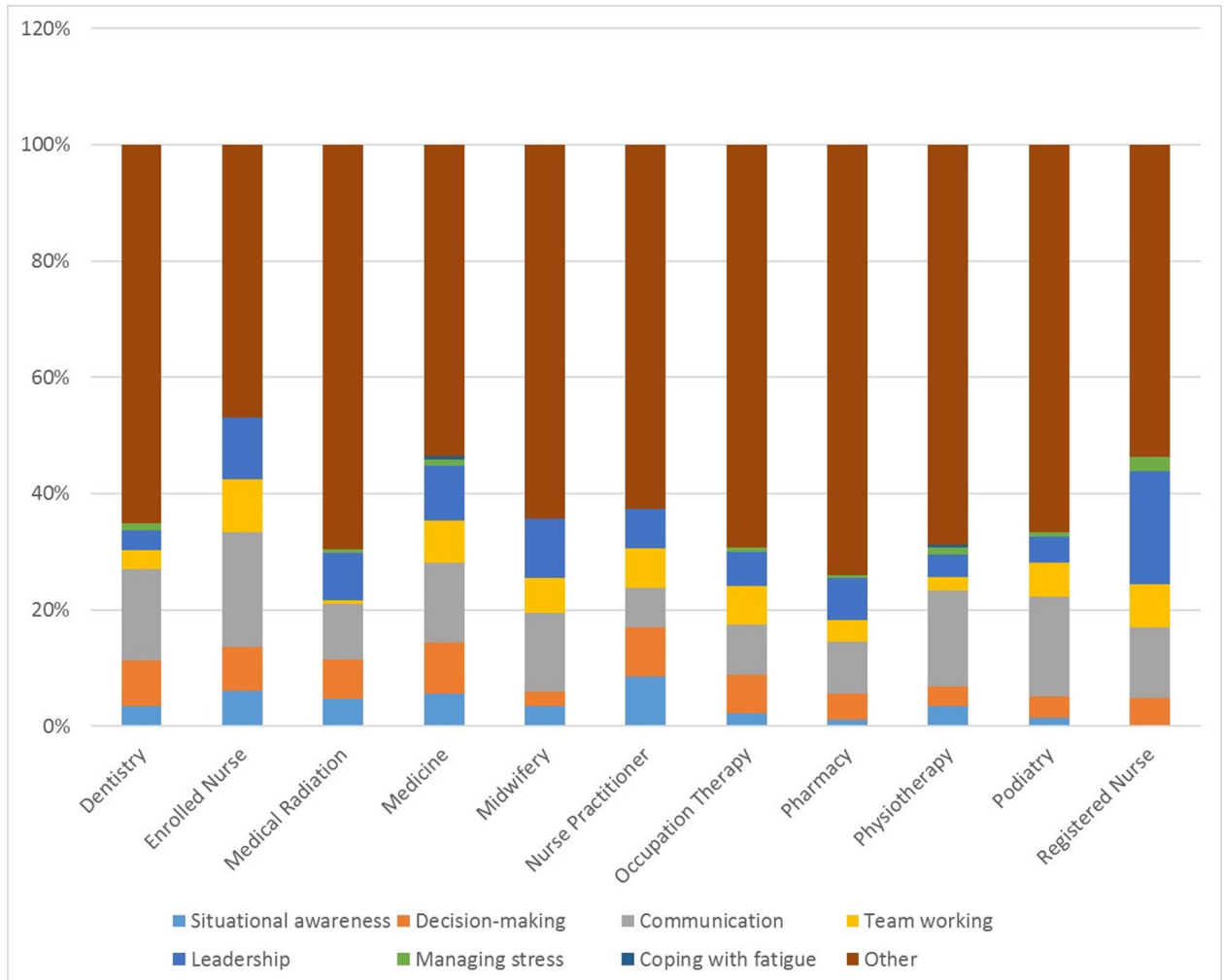

Figure 2 Percentage of non-technical skills in standards documents for each profession (the other category is defined as per figure 1).

\section{Study limitations}

The strength of the study is in bringing together standards documents from several professions and viewing them through one lens. Rigour of the analytic process was established by the coding of a random selection of competency statements by all authors and presentation of sample statements from each code (online supplementary box 2$)$.

One limitation of this study is the inclusion of only those professions registered by AHPRA. There are health professions that practise in secondary and tertiary care who are not registered by AHPRA (eg, speech therapy and dietetics). Additionally, while the research has focused on professions practising in acute care in secondary and tertiary settings, the competency standards documents address a wider arc of care. Caution must be also exercised when reviewing the compared statements and the proportionality of statements as they may have been drawn from different levels within the documents. Coding was challenging because there was no common taxonomy and shared language. The standards documents are structured differently with varied levels of statements that are complex and multifaceted.

Additionally, the study did not collect data on the significance of particular non-technical skills in various professions, hence some of the variation noted in the standards documents may be appropriate depending on working context and practice requirements, for example, coping with fatigue may not be significant if long stretches of duty are uncommon for that particular profession. It is worth underlining the obvious point that this work refers to aspirational standards rather than actual practice. While this study was conducted using Australian competency standards documents, we believe the issues raised are indicative of the nature of competency standards in similar countries globally.

\section{CONCLUSION}

The commonalties in non-technical categories and elements identified across the standards documents offer support for safer, collaborative healthcare practices and patient outcomes in Australia. While the findings are encouraging, there is some concern regarding non-technical skills elements that are inconsistent or missing across the standards documents. Hence, these standards may be insufficient to support current needs and demands for competent non-technical skills that are critical to maintain patient safety. ${ }^{22}$ Attention is required from regulatory bodies to consider omissions and other inconsistent and missing elements across non-technical skills categories. We suggest that regulatory bodies respond to emerging demands of current clinical practice and work together to develop a common taxonomy, with clear, unambiguous statements. This would likely facilitate collaborative education and practice.

This research confirms that non-technical skills are required in the practice of health professionals for registration with AHPRA. Consideration should be given to mandating non-technical skills education as a component 
of the accreditation for undergraduate health professional curricula. Curricula should include non-technical skills content, practice and assessments to ensure graduates can meet the requirements in accordance with associated standards.

\section{Author affiliations}

${ }^{1}$ School of Nursing and Midwifery, College of Science Health and Engineering, La Trobe University, Bundoora, Victoria, Australia

${ }^{2}$ Centre for Research in Assessment and Digital Learning (CRADLE), Deakin University, Melbourne, Victoria, Australia

${ }^{3}$ Faculty of Medicine, Nursing and Health Sciences, Monash University, Melbourne, Victoria, Australia

${ }^{4}$ Faculty of Medicine, Nursing and Health Sciences, Monash Institute for Health and Clinical Education, Monash University, Clayton, Victoria, Australia

Contributors MP carried out all aspects of the study, including study design, coding for document analysis, interpretation of the data and writing the manuscript. $\mathrm{DN}, \mathrm{MB}$ and NR supervised the study and contributed to study design, coding and interpretation of the document analysis and the writing of the manuscript. LM contributed to the interpretation of data and writing of the manuscript. The final manuscript has been read and approved by all authors.

Funding The authors have not declared a specific grant for this research from any funding agency in the public, commercial or not-for-profit sectors.

Competing interests None declared.

Patient consent Not required.

Provenance and peer review Not commissioned; externally peer reviewed.

Data sharing statement № additional unpublished data is available.

Open access This is an open access article distributed in accordance with the Creative Commons Attribution Non Commercial (CC BY-NC 4.0) license, which permits others to distribute, remix, adapt, build upon this work non-commercially, and license their derivative works on different terms, provided the original work is properly cited, appropriate credit is given, any changes made indicated, and the use is non-commercial. See: http://creativecommons.org/licenses/by-nc/4.0/.

\section{REFERENCES}

1. Shojania KG, Dixon-Woods M. Estimating deaths due to medical error: the ongoing controversy and why it matters. BMJ Qual Saf 2017;26:bmjqs-2016-006144.

2. Garrouste-Orgeas M, Philippart F, Bruel C, et al. Overview of medical errors and adverse events. Ann Intensive Care 2012;2:2.

3. Kohn L, Corrigan J, Donaldson M. To err is human: building a safer health system. Washington: National Academy Press, 2000.

4. Hull L, Arora S, Aggarwal R, et al. The impact of nontechnical skills on technical performance in surgery: a systematic review. J Am Coll Surg 2012;214:214-30.

5. Atwal A, Caldwell K. Nurses' perceptions of multidisciplinary team work in acute health-care. Int J Nurs Pract 2006;12:359-65.

6. Cant RP, Porter JE, Cooper SJ, et al. Improving the nontechnical skills of hospital medical emergency teams: The Team Emergency Assessment Measure (TEAM ${ }^{\mathrm{TM}}$ ). Emerg Med Australas 2016;28:641-6.

7. Flin $\mathrm{R}, \mathrm{O}^{\prime}$ Connor $\mathrm{P}$, Crichton M. Safety at the sharp end: a guide to non-technical skills. Cornwall: Ashgate Publishing, Ltd, 2013.

8. Yule S, Flin R, Paterson-Brown S, et al. Non-technical skills for surgeons in the operating room: a review of the literature. Surgery 2006;139:140-9.

9. Fletcher G, Flin R, McGeorge P, et al. Rating non-technical skills: developing a behavioural marker system for use in anaesthesia. Cogn Technol Work 2004;6:165-71.

10. Flin R. Non-technical skills for anaesthetists, surgeons and scrub practitioners (ANTS, NOTSS and SPLINTS). The Healthcare Foundation 2013:1-9.
11. University of Aberdeen Industrial Psychology Research Centre. Publications. http://www.abdn.ac.uk/iprc/papers/ (accessed July 2016).

12. Carraccio C, Wolfsthal SD, Englander R, et al. Shifting paradigms: from Flexner to competencies. Acad Med 2002;77:361-7.

13. Verma S, Paterson M, Medves J. Core competencies for health care professionals: what medicine, nursing, occupational therapy, and physiotherapy share. J Allied Health 2006;35:109-15.

14. Terry K, Stirling C, Bull R, et al. An overview of the ways nurses understand and utilise the existing Australian Competency Standards for Registered Nurses. Collegian 2017;24:109-16.

15. O'Connell J, Gardner G, Coyer F. Beyond competencies: using a capability framework in developing practice standards for advanced practice nursing. J Adv Nurs 2014;70:2728-35.

16. Halcomb E, Stephens M, Bryce J, et al. Nursing competency standards in primary health care: an integrative review. J Clin Nurs 2016;25:1193-205.

17. Australian Health Ministers' Advisory Council. Australia's Health Workforce: strengthening the education foundation: COAG Health Council, 2017.

18. Cronenwett L, Sherwood G, Barnsteiner J, et al. Quality and safety education for nurses. Nurs Outlook 2007;55:122-31.

19. Australian Health Practitioner Regulation Agency. http://www.ahpra. gov.au/About-AHPRA/Who-We-Are.aspx (accessed Sep 2016).

20. Englander R, Cameron T, Ballard AJ, et al. Toward a common taxonomy of competency domains for the health professions and competencies for physicians. Acad Med 2013;88:1088-94.

21. Verma S, Broers T, Paterson M, et al. Core competencies: the next generation. Comparison of a common framework for multiple professions. J Allied Health 2009;38:47-53.

22. Zorek J, Raehl C. Interprofessional education accreditation standards in the USA: a comparative analysis. J Interprof Care 2013;27:123-30.

23. Moran KM, Harris IB, Valenta AL. Competencies for patient safety and quality improvement: a synthesis of recommendations in influential position papers. Jt Comm J Qual Patient Saf 2016;42:162-9.

24. Greig PR, Higham H, Vaux E. Lack of standardisation between specialties for human factors content in postgraduate training: an analysis of specialty curricula in the UK. BMJ Qual Saf 2015;24:558-60.

25. Bowen GA. Document Analysis as a Qualitative Research Method. Qualitative Research Journal 2009;9:27-40.

26. O'Toole ME. Mosby's medical dictionary. 10 edn. St Louis: Elsevier, 2017.

27. Australian Government Department of Health. Glossary. http://www. health.gov.au/internet/publications/publishing.nsf/Content/oatsihhpf-2012-toc glossary\#s (accessed Jul 2017).

28. Leonard M, Graham S, Bonacum D. The human factor: the critical importance of effective teamwork and communication in providing safe care. Qual Saf Health Care 2004;13(suppl 1):i85-i90.

29. Brock D, Abu-Rish E, Chiu CR, et al. Interprofessional education in team communication: working together to improve patient safety. BMJ Qual Saf 2013;22:414-23.

30. Suter E, Arndt J, Arthur N, et al. Role understanding and effective communication as core competencies for collaborative practice. $J$ Interprof Care 2009;23:41-51.

31. Reeves $S$. The rise and rise of interprofessional competence. $J$ Interprof Care 2012;26:253-5.

32. Schmitt M, Blue A, Aschenbrener CA, et al. Core competencies for interprofessional collaborative practice: reforming health care by transforming health professionals' education. Acad Med 2011;86:1351.

33. Soares DS, Chan L. Stress and wellbeing of junior doctors in Australia: a comparison with American doctors and population norms. BMC Med Educ 2016;16:183.

34. Brown M, Tucker P, Rapport F, et al. The impact of shift patterns on junior doctors' perceptions of fatigue, training, work/life balance and the role of social support. Qual Saf Health Care 2010;19:e36.

35. Milner AJ, Maheen H, Bismark MM, et al. Suicide by health professionals: a retrospective mortality study in Australia, 2001-2012. Med J Aust 2016;205:260-5.

36. Kodate N, Ross A, Anderson J, et al. Non-Technical Skills (NTS) for enhancing patient safety: achievements and future directions. Japanese Journal of Quality and Safety in Healthcare 2012;7:360-70.

37. Reader T, Flin R, Lauche K, et al. Non-technical skills in the intensive care unit. Br J Anaesth 2006;96:551-9. 